\title{
Norm of Physical Measurement of Typical Developing Chinese Children in Hong Kong
}

\begin{abstract}
Keywords: Chinese children; Hong Kong; Norm; Physical measurements

Abstract

Introduction: A pilot study to establish a nom of physica measurement for typically developing (TD) Chinese children in Hong Kong.

Methods: To esta blish a nom of physic al mea surements for typic a developing Chinese children, kindergarten and nurseries a cross Hong Kong were recruited between 2009 to 2011. Height, weight, head circumference, ear length, outer and inner canthi, interpupillary distance, philtrum, hand and foot length were measured using standard procedures in children of typical development at preschoo and kindergarten age.

Results: A nom of physical measurements was established from recruitment of 658 TD children aged 1 to 7 years old (mean age of 4.19 years)

Discussion: Based on the results from this study we have successfully shown the continuing establishment of a nom of body physical measurements for Chinese children in Hong Kong. This norm is a valuable tool for future quantification and the detection of deviations in children with a wide range of developmental and genetic disorders. With the use of validated qua ntitative measures, this would aid paediatricians with the identification of dysmorphology and differentiating what is within or outside of nomal range.
\end{abstract}

\section{Abbreviations}

ASD: Autism Spectrum Disorder; BMI: Body Mass Index; cm: centimeters; kg: kilograms; TD: Typical Development; OFC: Occipital Frontal Circumference

\section{Introduction}

To monitor and track the growth of a child over time, growth charts are primarily used by paediatricians and other health care providers. In Hong Kong a territory wide, cross-sectional growth chart covering 25,000 Chinese children from birth to 18 years was performed in 1993 by Leung et al. and is used for height, weight and head circumference for developmental assessment [1]. An updated norm of other physical body measurements for Chinese children in Hong Kong that can be used for comparison is lacking.

As part of an on-going study, our research team attempted to identify subgroups within children of Autism Spectrum Disorder (ASD) based on physical measurements and dysmorphology examinations [2,3]. In order to establish a comparison against a group of children diagnosed with ASD, our research team first decided to create a Chinese set of norms of physical measurements from typical developing children. This paper aims to report the results of the pilot study to study the physical measurements of TD group.

The setup of a norm of body physical measurements collected from typically developing Chinese children population is useful not

\section{Journal of}

Syndromes

\author{
Polly Tsz Yan Wong ${ }^{1}$ and Virginia Chun-Ne \\ Wong $^{1,2 *}$
}

${ }^{1}$ Department of Paediatrics and Adolescent Medicine, Li KaShing Faculty of Medicine, The University of Hong Kong, Hong Kong, China

${ }^{2}$ Division of Paediatric Neurology/ Developmental

BehaviouralPaediatrics/ Neuro Habilitation, Department of

Paediatrics and Adolescent Medicine, Li KaShing Faculty of Medicine, The University of Hong Kong, Hong Kong, China

\section{*Address for Correspondence}

Professor Virginia CN Wong, Department of Paediatrics and Adolescent Medicine, Rm 105 New Clinical Building, Queen Mary Hospital, The University of Hong Kong, 102 Pokfulam Road, Hong Kong, China, Tel: +852 2255 4091; Fax: +852 2255 1523; E-mail: vcnwong@hku.hk

Submission: 11 February 2015

Accepted: 14 April 2015

Published: 21 April 2015

only in identifying homogeneity subgroups within ASD population, but is beneficial for future research involving other neurological or behaviorally defined disorders. The target population for this study is primarily focused at preschool and kindergarten age group (0 to 7 years old), but we wish to extend the research to the paediatric and adolescent population ( 0 to 18 years old) in the future.

In order to recognize the prevalence of children with dysmorphism in a population, there is a need to set up a norm data collected from control in general population. The target population of this study is children of Chinese ethnicity. As a result of both genetics and environmental factors, physical norm data would evidently differ from Chinese population when compared to Caucasian population. Wu et al. studied the ocular measurements in normal Chinese children in Taiwan and found that the inner canthal distance, outer canthal distance and interpupillary distance in Chinese children were wider than those in Caucasian children [4]. This exemplifies the ethnical differences in normal body physical measurements for quantitative data and the need to set up a Chinese norm. The main objective of this study is to establish a Chinese norm of physical measurements from typical developing children as basis for comparison against a group of children diagnosed with ASD. In particular, this study will attempt to address the following questions: 1) What is the norm of physical measurements for a single ethnicity (Chinese)? 2) Do the physical measurements of the children in the normal development group differ from the physical measurements of ASD children?

\section{Participants and Methods}

This study is a part of an ongoing population-based case-control investigation on children selected from general population with Typical Development (TD) compared with children with Autism Spectrum Disorder (ASD). This paper summarizes the results from the TD group in order to establish a norm of physical measurements and compares to children of ASD.

\section{Study recruitment}

To establish a norm of physical measurements for Chinese 
children, kindergarten and nurseries across Hong Kong were invited to take part of the study. This study was first launched as a pilot study. As of March 2010, there are 966 Kindergarten and KindergartenCum Child Centre registered under the Education Bureau in Hong Kong. Letters of invitations and background of study were mailed and faxed to a random sample of 198 nurseries. The total number of schools recruited for this study was 68 . Of the 68 nurseries and kindergartens recruited, 14 nurseries were located in North Territories, 52 in Kowloon and 2 in Hong Kong Island. The current study was conducted between Jan 2010 to December 2011. Signed consent forms returned by children of interested parents or legal guardians were recruited into study.

The inclusion criteria for this study are typical developing children aged between 0 to 7 years old (preschool and kindergarten age) and of Chinese ethnicity with no history of global developmental delay or other medical disorders and no previous history of neuropsychiatric or genetic disorders. All children must have an overall healthy developmental profile without any marked problems or regression signified from a healthy Mother Child Health Clinic (MCHC) records. No further exclusions for TD group were made based on genetics, family phenotype, or other characteristics with the exception of children who had visual, hearing or motor impairments that precluded the physical examination assessment.

To establish a comparison, the physical measurements of TD group were analyzed against children diagnosed with ASD collected in a related on-going study. The inclusion criteria for the ASD group were children aged between 0 to 7 years old, of Chinese ethnicity and a confirmed medical diagnosis of ASD (Autism/Asperger/PDDNOS) made by child neurologist, developmental pediatricians, and/ or clinical psychologist. All ASD children must meet the diagnostic criteria for ASD according to the Diagnostic and Statistical Manual of Mental Disorders (DSM-IV) [5] and/or DSM-5 [6].

\section{Physical measurements}

Physical measurements including height, weight, head circumference, ear length, length of outer and inner canthi, interpupillary distance, philtrum, hand, finger length and foot length was measured for all participants in TD group. The standing height (from top of the head to tip of the feet) was measured and recorded in centimetres. The weight was recorded in kilograms $(\mathrm{kg})$ with shoes, jewelleries, and belts removed before measurement. The head circumference or Occipital Frontal Circumference (OFC) $(\mathrm{cm})$ was measured from the above most prominent point on the frontal bone above the root of the nose to the posterior most prominent point of the occipital bone using tape measure. The ear length $(\mathrm{cm})$ is length of the external ear (pinna) from the superior aspect of the outer rim of the helix to the most inferior border of the ear lobe or pinna. The outer canthus distance $(\mathrm{cm})$ is the measurement between the outer canthi of the two eyes from the most lateral corner of one eye to the most lateral corner of the other eye) the inner canthus $(\mathrm{cm})$ is the measurement from the innermost corner of one eye to the inner most corner of the other eye. The interpupillary distance $(\mathrm{cm})$ is the measurement between the centres of both pupils. The philtrum $(\mathrm{cm})$ is the measurement of the distance between the base of the nose and the border of the upper lip, in the midline. The hand length $(\mathrm{cm})$ is the measurement from the distal crease at the wrist to the tip of the middle finger. The finger length $(\mathrm{cm})$ is the length of the middle finger, the measurement from the proximal flexion crease at the base of the middle finger to the tip of the middle finger taken on the palmar aspect of the hand. The foot length $(\mathrm{cm})$ is the measurement of the longest axis of the foot, measured from an imaginary vertical line drawn from the posterior prominence of the heel, to the tip of the longest toe, on the plantar aspect of the foot. The standard protocol for measuring the physical measurements is followed in reference from Hall et al. [7]. All measurements were measured twice, rounded to the nearest $0.1 \mathrm{~kg}$ or $0.1 \mathrm{~cm}$ and the average was recorded into the database. The examination was performed using standardized and calibrated medical scales, stand height measure, non-stretchable measuring tape and calliper. All investigators (P.W., C.F., and G.C.) responsible for the physical examination were trained to ensure standardization of all measurements.

\section{Statistical analysis}

Normally distributed mean data are presented mean \pm standard deviation (SD). Physical measurements are rounded to the nearest tenth. The physical measurements for the TD and ASD group were compared using the unpaired student-t-test. In order to match for age and sex, participants were divided into age and sex groups. All statistical analyses were performed with SPSS version 17.0 (SPSS Inc., Chicago, USA) with unpaired student $t$-test. A p value less than 0.05 was considered statistically significant.

\section{Ethical approval}

This study was reviewed and approved by the Institutional Review Board of the University of Hong Kong/Hospital Authority Hong Kong West Cluster (HKU/HA HKW IRB: UW 10-150).

\section{Results}

\section{Participants}

We received a total of 662 signed informed consent forms during the recruitment period. Four participants were excluded in the TD group because of inability to attend the physical examination due to sickness or vacation leave. For this pilot study, there were 658 participants recruited into the TD group. There was no withdrawal by parents or legal guardians after agreement to join study. In the ASD group, 80 children were recruited and compared against the TD group. Table 1 shows the demographics of the TD and ASD group.

\section{Physical measurements for TD group}

Table 2 shows the physical measurements for male participants in the TD group; Table 3 shows the physical measurements for female participants in the TD group. In order to further analyze the physical measurements of the TD group based on sex, the age group in this section was separated into 4 groups: $1 \leq 2$ years old, $3 \leq 4$ years old, 5 $\leq 6$ years old and $7 \leq 8$ years old (Table 4 ).

\section{Physical measurements of TD compared with ASD}

The physical measurements for TD group were compared to a group of ASD group for analysis. The statistical analysis for the physical measurements for TD and ASD group is shown in Table 5. Our results show that there were significant differences between ASD and TD children for measurements in: head circumference 
Citation: Wong PTY, Wong VCN. Norm of Physical Measurement of Typical Developing Chinese Children in Hong Kong. J Syndromes. 2015;2(1): 8.

ISSN: $2380-6036$

Table 1: Demographic data by sex characteristics for study population TD and ASD group.

\begin{tabular}{|c|c|c|c|}
\hline & \multicolumn{2}{|c|}{ TD Group $(\boldsymbol{n = 6 5 8 )}$} & ASD Group ( $\boldsymbol{n}=\mathbf{8 0})$ \\
\hline$n$ & Male & Female & Male \\
\hline Mean age in (years) & 353 & 305 & 71 \\
\hline Standard deviation & 4.12 & 4.28 & 4.39 \\
\hline Median & 1.3 & 1.22 & 1.52 \\
\hline Range (years) & 4 & 4 & 4.11 \\
\hline
\end{tabular}

Note: TD: Typical Development; ASD: Autism Spectrum Disorder

Table 2: Physical Measurements for 15 body parts for Males with Typical Development.

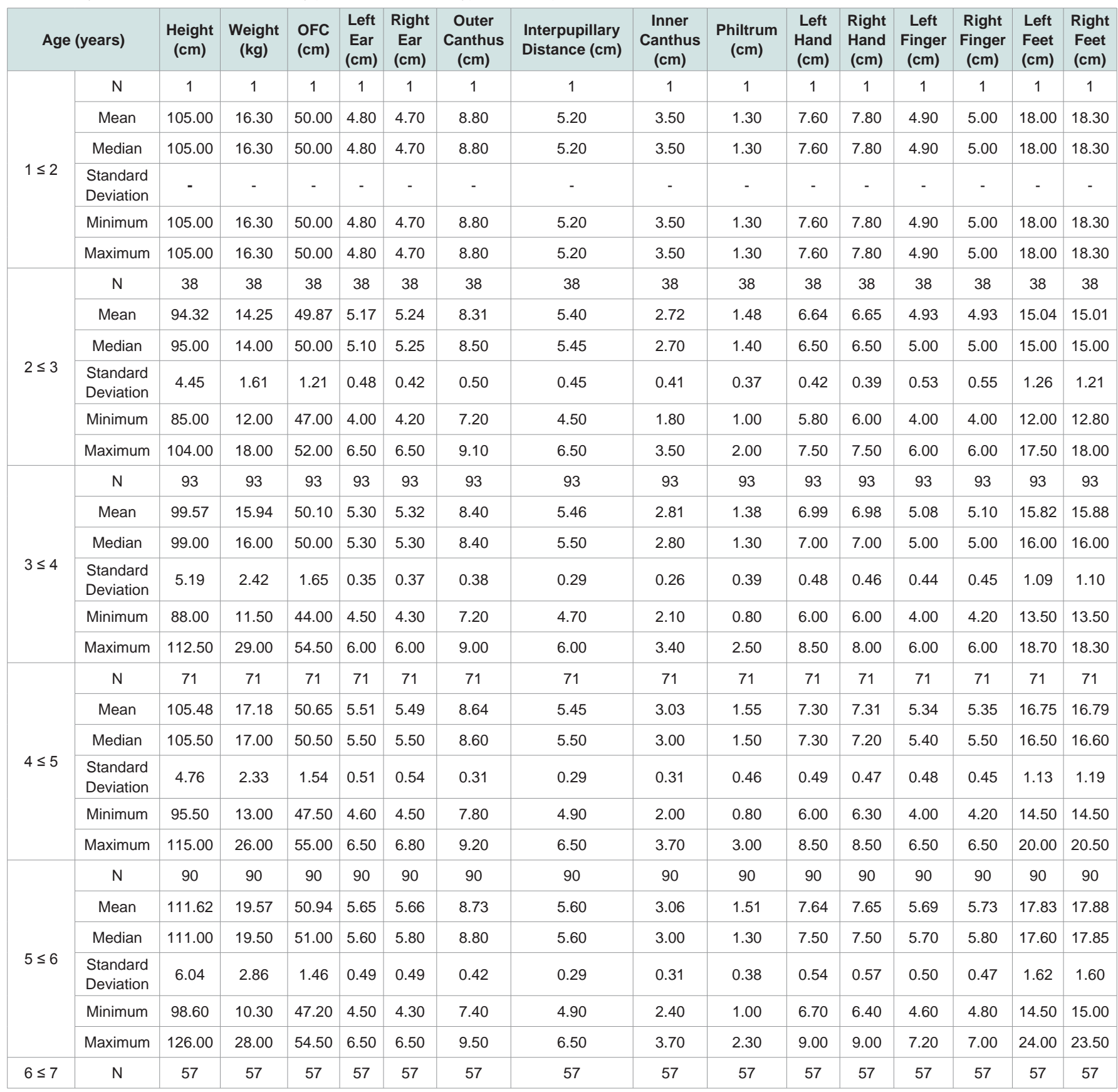


Citation: Wong PTY, Wong VCN. Norm of Physical Measurement of Typical Developing Chinese Children in Hong Kong. J Syndromes. 2015;2(1): 8.

ISSN: $2380-6036$

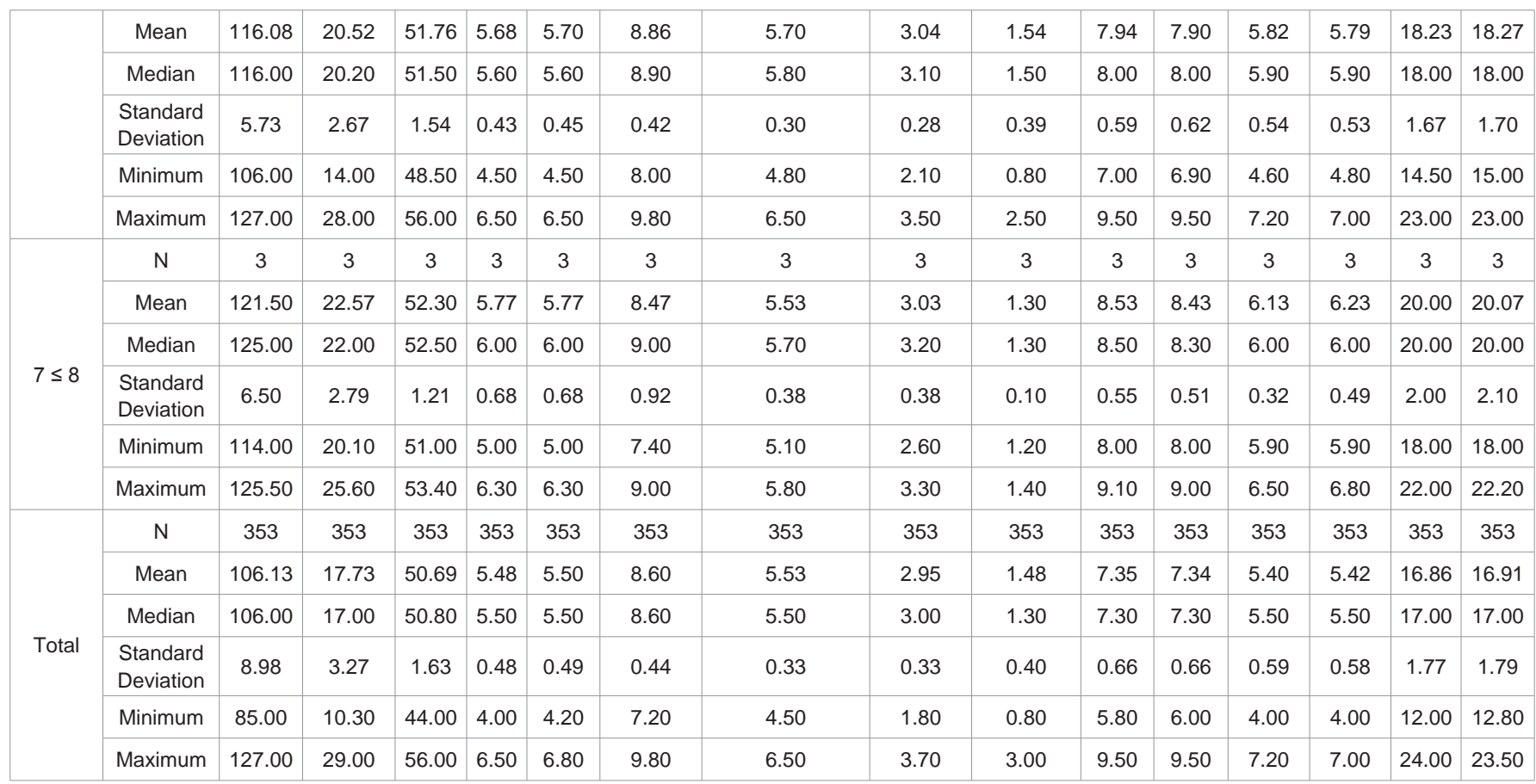

Table 3: Physical Measurements for 15 body parts for females with typical development

\begin{tabular}{|c|c|c|c|c|c|c|c|c|c|c|c|c|c|c|c|c|}
\hline \multicolumn{2}{|c|}{ Age (years) } & \multirow{2}{*}{$\begin{array}{c}\begin{array}{c}\text { Height } \\
\text { (cm) }\end{array} \\
24\end{array}$} & \multirow{2}{*}{$\begin{array}{c}\begin{array}{c}\text { Weight } \\
\text { (kg) }\end{array} \\
24\end{array}$} & \multirow{2}{*}{$\begin{array}{c}\begin{array}{c}\text { OFC } \\
(\mathrm{cm})\end{array} \\
24\end{array}$} & \multirow{2}{*}{\begin{tabular}{|c}
$\begin{array}{c}\text { Left } \\
\text { Ear } \\
\text { (cm) }\end{array}$ \\
24
\end{tabular}} & \multirow{2}{*}{$\begin{array}{c}\text { Right } \\
\text { Ear } \\
\text { (cm) }\end{array}$} & \multirow{2}{*}{$\begin{array}{c}\begin{array}{c}\text { Outer } \\
\text { Canthus } \\
\text { (cm) }\end{array} \\
24\end{array}$} & \multirow{2}{*}{$\begin{array}{c}\text { Interpupillary } \\
\text { Distance (cm) } \\
24\end{array}$} & \multirow{2}{*}{$\begin{array}{c}\begin{array}{c}\text { Inner } \\
\text { Canthus } \\
\text { (cm) }\end{array} \\
24\end{array}$} & \multirow{2}{*}{$\begin{array}{c}\text { Philtrum } \\
\text { (cm) } \\
24\end{array}$} & \multirow{2}{*}{$\begin{array}{c}\begin{array}{c}\text { Left } \\
\text { Hand } \\
\text { (cm) }\end{array} \\
24\end{array}$} & \multirow{2}{*}{$\begin{array}{c}\text { Right } \\
\text { Hand } \\
\text { (cm) }\end{array}$} & \multirow{2}{*}{$\begin{array}{c}\begin{array}{c}\text { Left } \\
\text { Finger } \\
\text { (cm) }\end{array} \\
24\end{array}$} & \multirow{2}{*}{$\begin{array}{c}\text { Right } \\
\text { Finger } \\
\text { (cm) }\end{array}$} & \multirow{2}{*}{$\begin{array}{c}\text { Left } \\
\text { Feet } \\
\text { (cm) }\end{array}$} & \multirow{2}{*}{$\begin{array}{c}\text { Right } \\
\text { Feet } \\
\text { (cm) } \\
24\end{array}$} \\
\hline \multirow{6}{*}{$1 \leq 2$} & $\mathrm{~N}$ & & & & & & & & & & & & & & & \\
\hline & Mean & 91.00 & 14.17 & 49.01 & 5.03 & 4.95 & 8.53 & 5.39 & 2.93 & 1.52 & 6.41 & 6.43 & 4.83 & 4.82 & 14.75 & 14.81 \\
\hline & Median & 91.75 & 14.00 & 49.00 & 5.00 & 5.00 & 8.50 & 5.30 & 3.10 & 1.50 & 6.50 & 6.50 & 4.80 & 4.75 & 14.50 & 14.50 \\
\hline & $\begin{array}{l}\text { Standard } \\
\text { Deviation }\end{array}$ & 3.80 & 3.49 & 1.50 & 0.46 & 0.45 & 0.52 & 0.51 & 0.33 & 0.39 & 0.46 & 0.46 & 0.59 & 0.52 & 1.40 & 1.36 \\
\hline & Minimum & 84.00 & 10.00 & 46.00 & 4.00 & 4.00 & 8.00 & 4.50 & 2.00 & 1.00 & 5.40 & 5.50 & 4.00 & 4.00 & 13.00 & 12.50 \\
\hline & Maximum & 97.00 & 29.00 & 51.50 & 6.00 & 5.50 & 9.50 & 6.50 & 3.20 & 2.00 & 7.00 & 7.00 & 6.00 & 6.00 & 19.00 & 19.00 \\
\hline \multirow{6}{*}{$2 \leq 3$} & $\mathrm{~N}$ & 64 & 64 & 64 & 64 & 64 & 64 & 64 & 64 & 64 & 64 & 64 & 64 & 64 & 64 & 64 \\
\hline & Mean & 98.51 & 15.07 & 49.22 & 5.19 & 5.18 & 8.37 & 5.35 & 2.83 & 1.43 & 6.84 & 6.82 & 5.07 & 5.08 & 15.48 & 15.55 \\
\hline & Median & 98.50 & 15.00 & 49.50 & 5.00 & 5.00 & 8.50 & 5.40 & 2.80 & 1.30 & 7.00 & 7.00 & 5.00 & 5.00 & 15.45 & 15.50 \\
\hline & $\begin{array}{l}\text { Standard } \\
\text { Deviation }\end{array}$ & 5.04 & 2.32 & 1.35 & 0.41 & 0.40 & 0.38 & 0.31 & 0.26 & 0.38 & 0.51 & 0.50 & 0.48 & 0.46 & 1.14 & 1.11 \\
\hline & Minimum & 84.00 & 11.20 & 45.00 & 4.00 & 4.00 & 7.40 & 4.60 & 2.00 & 0.80 & 6.00 & 6.00 & 4.00 & 4.00 & 13.50 & 13.50 \\
\hline & Maximum & 110.50 & 25.00 & 52.00 & 6.50 & 6.50 & 9.50 & 6.00 & 3.40 & 2.20 & 8.00 & 7.60 & 6.00 & 6.00 & 18.30 & 18.00 \\
\hline \multirow{6}{*}{$3 \leq 4$} & $\mathrm{~N}$ & 77 & 77 & 77 & 77 & 77 & 77 & 77 & 77 & 77 & 77 & 77 & 77 & 77 & 77 & 77 \\
\hline & Mean & 104.99 & 16.77 & 50.12 & 5.29 & 5.27 & 8.61 & 5.36 & 3.11 & 1.36 & 7.13 & 7.14 & 5.28 & 5.28 & 16.29 & 16.31 \\
\hline & Median & 104.00 & 17.00 & 50.00 & 5.30 & 5.30 & 8.50 & 5.40 & 3.20 & 1.30 & 7.10 & 7.00 & 5.20 & 5.20 & 16.50 & 16.50 \\
\hline & $\begin{array}{l}\text { Standard } \\
\text { Deviation }\end{array}$ & 5.26 & 1.89 & 1.48 & 0.39 & 0.43 & 0.29 & 0.29 & 0.26 & 0.33 & 0.51 & 0.53 & 0.51 & 0.49 & 1.12 & 1.10 \\
\hline & Minimum & 92.70 & 12.00 & 45.00 & 4.50 & 4.00 & 8.00 & 4.50 & 2.50 & 0.90 & 6.00 & 6.00 & 4.00 & 4.00 & 12.50 & 13.50 \\
\hline & Maximum & 117.00 & 21.00 & 53.00 & 6.10 & 6.20 & 9.20 & 6.00 & 3.50 & 2.20 & 8.50 & 8.50 & 6.10 & 6.10 & 18.90 & 19.00 \\
\hline \multirow{5}{*}{$4 \leq 5$} & $\mathrm{~N}$ & 86 & 86 & 86 & 86 & 86 & 86 & 86 & 86 & 86 & 86 & 86 & 86 & 86 & 86 & 86 \\
\hline & Mean & 111.90 & 19.03 & 50.69 & 5.42 & 5.42 & 8.79 & 5.56 & 3.14 & 1.51 & 7.47 & 7.47 & 5.71 & 5.69 & 17.41 & 17.51 \\
\hline & Median & 112.50 & 18.20 & 50.80 & 5.50 & 5.50 & 8.80 & 5.60 & 3.10 & 1.40 & 7.50 & 7.50 & 5.70 & 5.70 & 17.00 & 17.20 \\
\hline & $\begin{array}{l}\text { Standard } \\
\text { Deviation }\end{array}$ & 6.03 & 2.77 & 1.33 & 0.52 & 0.51 & 0.35 & 0.32 & 0.28 & 0.41 & 0.48 & 0.49 & 0.49 & 0.47 & 1.38 & 1.38 \\
\hline & Maximum & 125.00 & 27.00 & 54.00 & 6.50 & 6.50 & 9.50 & 6.50 & 3.80 & 2.70 & 8.50 & 8.50 & 7.00 & 6.80 & 23.00 & 23.00 \\
\hline
\end{tabular}




\begin{tabular}{|c|c|c|c|c|c|c|c|c|c|c|c|c|c|c|c|c|}
\hline \multirow{6}{*}{$5 \leq 6$} & $\mathrm{~N}$ & 51 & 51 & 51 & 51 & 51 & 51 & 51 & 51 & 51 & 51 & 51 & 51 & 51 & 51 & 51 \\
\hline & Mean & 115.38 & 20.07 & 50.88 & 5.42 & 5.40 & 8.95 & 5.67 & 3.12 & 1.46 & 7.57 & 7.60 & 5.69 & 5.71 & 17.86 & 17.95 \\
\hline & Median & 115.00 & 20.10 & 50.80 & 5.50 & 5.50 & 9.00 & 5.70 & 3.00 & 1.30 & 7.50 & 7.50 & 5.80 & 5.90 & 17.90 & 18.00 \\
\hline & $\begin{array}{l}\text { Standard } \\
\text { Deviation }\end{array}$ & 4.54 & 2.69 & 1.41 & 0.47 & 0.46 & 0.42 & 0.34 & 0.26 & 0.38 & 0.44 & 0.42 & 0.43 & 0.43 & 1.04 & 1.13 \\
\hline & Minimum & 106.00 & 10.50 & 48.00 & 4.00 & 4.00 & 7.90 & 5.00 & 2.40 & 1.00 & 6.60 & 6.60 & 4.50 & 4.80 & 15.50 & 15.50 \\
\hline & Maximum & 126.50 & 27.00 & 54.00 & 6.50 & 6.50 & 9.80 & 6.80 & 3.60 & 2.30 & 8.50 & 8.60 & 6.50 & 6.60 & 20.20 & 20.50 \\
\hline \multirow{6}{*}{$6 \leq 7$} & $\mathrm{~N}$ & 57 & 57 & 57 & 57 & 57 & 57 & 57 & 57 & 57 & 57 & 57 & 57 & 57 & 57 & 57 \\
\hline & Mean & 116.08 & 20.52 & 51.76 & 5.68 & 5.70 & 8.86 & 5.70 & 3.04 & 1.54 & 7.94 & 7.90 & 5.82 & 5.79 & 18.23 & 18.27 \\
\hline & Median & 116.00 & 20.20 & 51.50 & 5.60 & 5.60 & 8.90 & 5.80 & 3.10 & 1.50 & 8.00 & 8.00 & 5.90 & 5.90 & 18.00 & 18.00 \\
\hline & $\begin{array}{l}\text { Standard } \\
\text { Deviation }\end{array}$ & 5.73 & 2.67 & 1.54 & 0.43 & 0.45 & 0.42 & 0.30 & 0.28 & 0.39 & 0.59 & 0.62 & 0.54 & 0.53 & 1.67 & 1.70 \\
\hline & Minimum & 106.00 & 14.00 & 48.50 & 4.50 & 4.50 & 8.00 & 4.80 & 2.10 & 0.80 & 7.00 & 6.90 & 4.60 & 4.80 & 14.50 & 15.00 \\
\hline & Maximum & 127.00 & 28.00 & 56.00 & 6.50 & 6.50 & 9.80 & 6.50 & 3.50 & 2.50 & 9.50 & 9.50 & 7.20 & 7.00 & 23.00 & 23.00 \\
\hline \multirow{6}{*}{$7 \leq 8$} & $\mathrm{~N}$ & 3 & 3 & 3 & 3 & 3 & 3 & 3 & 3 & 3 & 3 & 3 & 3 & 3 & 3 & 3 \\
\hline & Mean & 121.50 & 22.57 & 52.30 & 5.77 & 5.77 & 8.47 & 5.53 & 3.03 & 1.30 & 8.53 & 8.43 & 6.13 & 6.23 & 20.00 & 20.07 \\
\hline & Median & 125.00 & 22.00 & 52.50 & 6.00 & 6.00 & 9.00 & 5.70 & 3.20 & 1.30 & 8.50 & 8.30 & 6.00 & 6.00 & 20.00 & 20.00 \\
\hline & $\begin{array}{c}\text { Std. } \\
\text { Deviation }\end{array}$ & 6.50 & 2.79 & 1.21 & 0.68 & 0.68 & 0.92 & 0.38 & 0.38 & 0.10 & 0.55 & 0.51 & 0.32 & 0.49 & 2.00 & 2.10 \\
\hline & Minimum & 114.00 & 20.10 & 51.00 & 5.00 & 5.00 & 7.40 & 5.10 & 2.60 & 1.20 & 8.00 & 8.00 & 5.90 & 5.90 & 18.00 & 18.00 \\
\hline & Maximum & 125.50 & 25.60 & 53.40 & 6.30 & 6.30 & 9.00 & 5.80 & 3.30 & 1.40 & 9.10 & 9.00 & 6.50 & 6.80 & 22.00 & 22.20 \\
\hline \multirow{6}{*}{ Total } & $\mathrm{N}$ & 353 & 353 & 353 & 353 & 353 & 353 & 353 & 353 & 353 & 353 & 353 & 353 & 353 & 353 & 353 \\
\hline & Mean & 106.13 & 17.73 & 50.69 & 5.48 & 5.50 & 8.60 & 5.53 & 2.95 & 1.48 & 7.35 & 7.34 & 5.40 & 5.42 & 16.86 & 16.91 \\
\hline & Median & 106.00 & 17.00 & 50.80 & 5.50 & 5.50 & 8.60 & 5.50 & 3.00 & 1.30 & 7.30 & 7.30 & 5.50 & 5.50 & 17.00 & 17.00 \\
\hline & $\begin{array}{l}\text { Standard } \\
\text { Deviation }\end{array}$ & 8.98 & 3.27 & 1.63 & 0.48 & 0.49 & 0.44 & 0.33 & 0.33 & 0.40 & 0.66 & 0.66 & 0.59 & 0.58 & 1.77 & 1.79 \\
\hline & Minimum & 85.00 & 10.30 & 44.00 & 4.00 & 4.20 & 7.20 & 4.50 & 1.80 & 0.80 & 5.80 & 6.00 & 4.00 & 4.00 & 12.00 & 12.80 \\
\hline & Maximum & 127.00 & 29.00 & 56.00 & 6.50 & 6.80 & 9.80 & 6.50 & 3.70 & 3.00 & 9.50 & 9.50 & 7.20 & 7.00 & 24.00 & 23.50 \\
\hline
\end{tabular}

Table 4: Comparison of height, weight, BMI (Body Mass Index), OFC (Occipital Frontal Circumference), Left and Right Ear length, Outer Canthus, Interpupillary Distance, Inner Canthus, Philtrum, Left and Right Hand length, Left and Right Finger length, Left and Right Foot by sex ( Specified Units \pm Standard Error of the Mean).

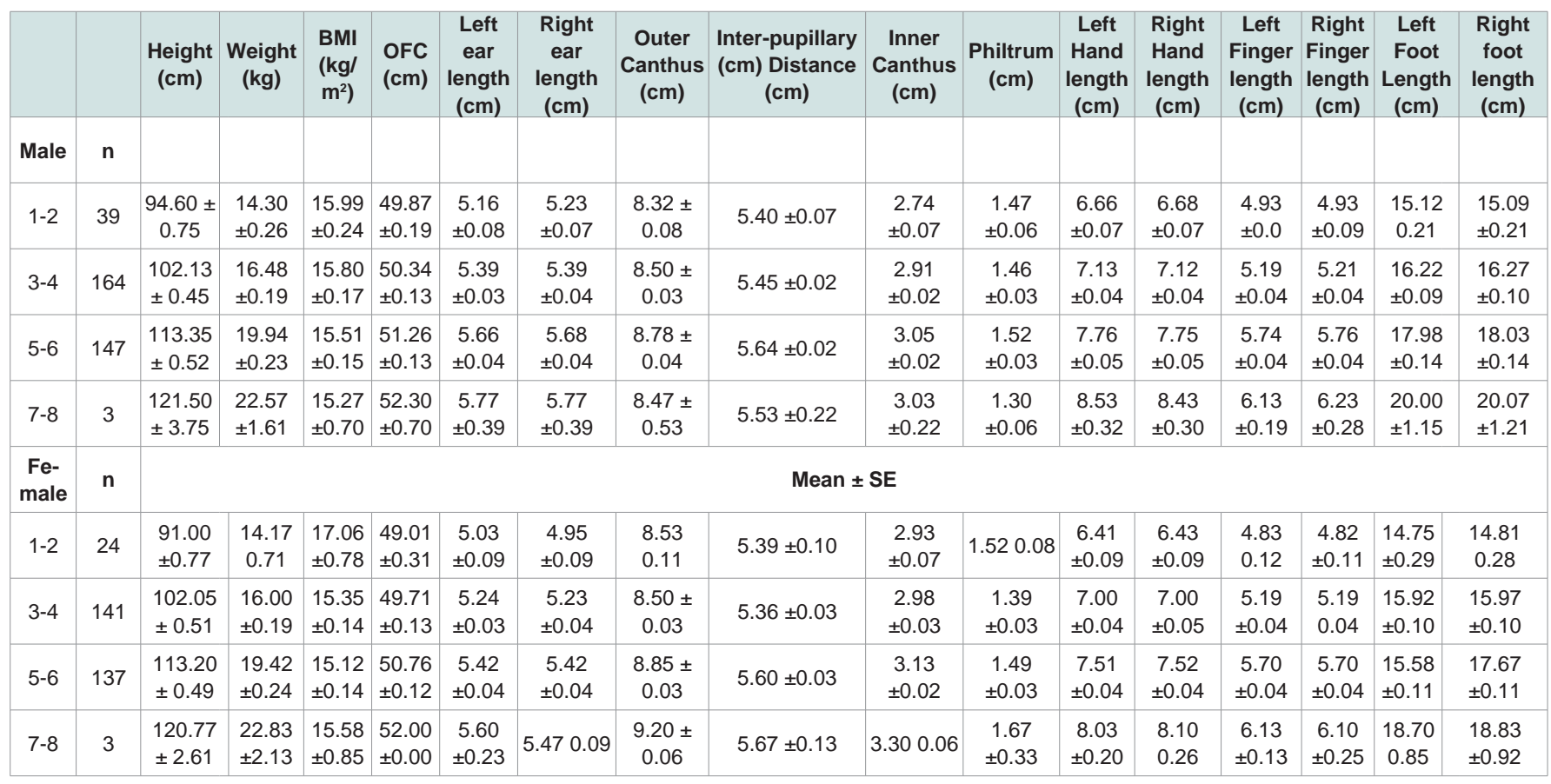


$(\mathrm{p}=0.009)$, outer $(\mathrm{p}=0.021)$ and inner $(\mathrm{p}=0.021)$ canthus, philtrum length $(\mathrm{p}=0.003)$, right $(\mathrm{p}=0.023)$ and left $(\mathrm{p}=0.020)$ foot length.

\section{Discussion}

Our study group has an on-going study to investigate the physical measurements and dysmorphology in children with ASD. In order to recognize general dysmorphology and detect deviations of body measurements in ASD children, there is a need to set up a norm data of physical measurements collected from TD children as control. The physical measurements including height, weight, OFC, outer and inner canthi distances, interpupillary distance, ear, finger, hand and foot length were collected from typically developing Chinese children

Table 5: Comparison of statistical analysis for the 15 physical measurements between TD and ASD group.

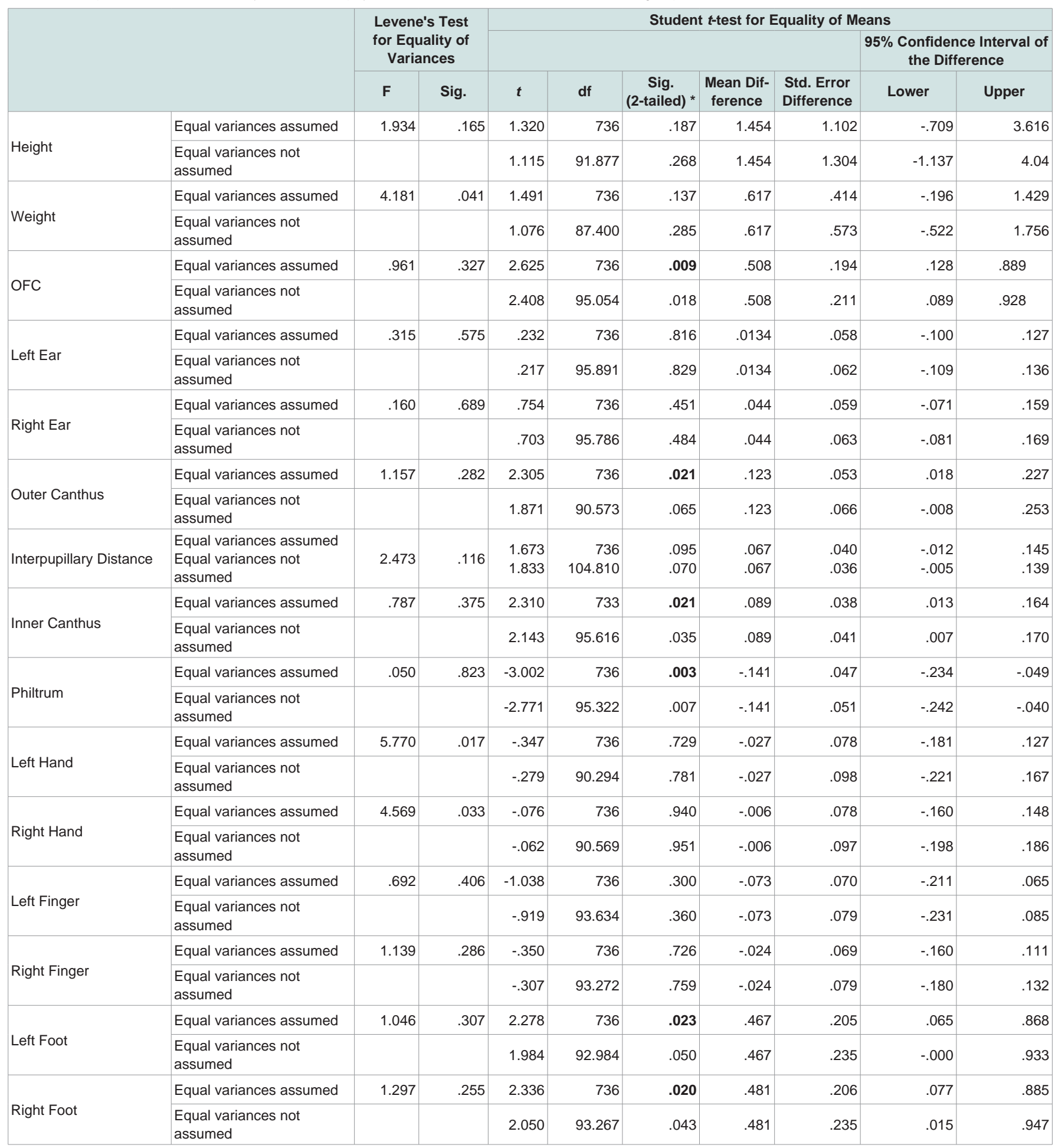


in the general population without medical conditions or diagnosis. In this pilot study, we compared the physical measurements in TD group and compared against a group of ASD children for comparison. We report statistical differences reported for head circumference, outer and inner canthus, philtrun length, and foot length. Our main results were that there is statistical difference in the physical measurements between the TD and ASD group. The differences in the physical measurements observed in the TD group reported in this study showed the importance of normative data. The comparisons for the progression of change in height, weight and head circumference are standard evaluations for growth assessment. The comparison provides important reflection on the health, nutritional state and overall clinical impression for a child. While it is not used as a diagnostic instrument, the quantification and the detection of deviations can provide early insights for possible underlying problems during the initial and subsequent assessments.

In 2010, the CDC recommended that healthcare providers in United States shall use the WHO growth standards to monitor growth for infants and children less than 24 months and the CDC growth charts for children beyond 24 months [8]. The WHO child growth charts were updated with new international growth standard statistical distribution in 2006 for the growth of healthy children living under optimal conditions [9]. The use of both WHO and CDC growth charts are intended for all children regardless of socioeconomic status and ethnicity, however there are studies to suggest that they may not be suitable for all populations [10,11]. In recent studies, there are researchers that questioned whether the uses of WHO growth standards are applicable for a Chinese population, specifically for children in Hong Kong [12]. Based on the 1997 Hong Kong birth cohort as the population based study - they found that the weight for age was close to the $50^{\text {th }}$ percentile of the WHO standards for both boys and girls before 3 years of age, however, toddlers at age of 3 were on average, shorter [11]. Similarly, in Hong Kong, the Body Mass Index (BMI) of Chinese and Caucasian infants was assessed and it was evident that ethical differences between populations exists [13]. In Beijing, China, BMI percentile curves were created of 7-18 years of aged Chinese children and then compared to the WHO and CDC charts. The investigators found that BMI distributions in China were substantially different from WHO and CDC references. Specifically, Chinese girls were lower in reference values and younger Chinese boys had higher proportions of extreme BMI values in both directions [14]. In United Kingdom (UK), Wright and colleagues assessed the potential effect for use of the WHO growth charts for monitoring UK children. Their results show that at birth, UK children were longer and heavier than the WHO standard and the WHO growth charts would set a lower standard for weight gain for UK infants [10]. Subsequently, new charts UK growth charts were created for children aged 0-4 years old to describe the optimal pattern of growth for UK children [9]. The comparable differences observed in across the mentioned studies challenged whether a universal growth standard is applicable across all populations. A growth standard that is tailored to individual populations (with varying nourishment and feeding patterns) will better reflect ethnic-racial diverse populations. The variation for human growth patterns exists not only between ethnic groups but also between regions. A growth standard created within a region of an ethnic group would better reflect the physical growth status of children in a sampled population.

Focusing specifically on Chinese children, there are populationbased studies for growth charts that was previously created. There are growth patterns and measurement studies for Chinese children, including - physical growth status for height, weight, sitting-height and chest circumference in China [15] reference curves for weight, length/height, head circumference for children under 7 years of age in Beijing, China [16,17]; height and weight growth charts from birth to 18 years by the National Growth Survey of Children and the Physical Fitness and Health Surveillance of Chinese School Students in China from birth to 18 years old [16] longitudinal growth standards for height, weight, sitting height, arm span, skin-fold thickness, body mass index and ratio of sitting height or arm span to stature in Taiwan [18] and waist circumference and waist-to-height ratio for children in Hong Kong [19].

In 1993, a growth survey of approximately 25,000 Hong Kong children from birth to 18 years of age was performed [20]. Locally derived growth charts from a territory wide cross-sectional growth survey are still currently in used in Hong Kong. This set of growth charts are developed by The Chinese University of Hong Kong in 1993 with growth parameters measured for weight, height, head circumference, sitting height, upper to lower segment ratio, age of pubertal changes - breast development in girls and penile development in boys, triceps and sub scapular skin fold thickness and BMI $[20,21]$. In the current study, the author reported the norm data of physical measurement for 658 Chinese TD children aged 1 to 7 years old undertaken between 2010-2011 in Hong Kong. The physical measurements in TD children are shown to be significantly different than a group of ASD children used for comparison. The current study is a pilot study launched and a major limitation of this study is the small sample size. Based on the preliminary results from this data, our study group is currently in progress of a more representative study with a larger sample size.

In our study, we attempt to establish a normative standard data for physical body measurements in Hong Kong Chinese children. The application of western data on Chinese children has been shown to be inapplicable for diagnosis and evaluation. Hence, there are practical uses for the norm data established in this pilot study for future diagnostic use and clinical comparisons beyond ASD and for other neurological, genetic disorders.

The use of physical measurements in children is important for providing early insights for genetic syndromes and clinical evaluation. As part of a pilot study, we expect the advancements in methodology to further exemplify the results found in this study. The use of advanced imaging systems with high-precision would validate results with accuracy and speed. We propose the use of 3dMDface camera system - an imaging system for ultra-fast, high-precision 3D surface imaging device (3dMD 2011). The 3dMDface system is a non-invasive imaging system that provides high-precision anatomical documentation of body surfaces and provides a 180-degree capture (ear to ear) coverage in less than 1.5 milliseconds. This system would allow researchers to acquire 3D data for anthropometric facial coordinates and analysis facial morphology. We hope to apply the use of this imaging system at $\mathrm{DKCH}$ and QMH to better record the quantitative data on physical measurements for all children during developmental assessment. The 
information collected would assist the basis for condition assessment, treatment planning, and progress monitoring. The use of a highprecision imaging system would eliminate any human-made or interrater variations and greatly improve power for research analyses. The use of this imaging system would allow researchers to further exemplify dysmorphology and minor physical anomalies in children. The use of quantitative measures is important for identification of dysmorphic features and differentiating what is within or outside of normal range. Hence, the setup of a norm data is of utmost priority to recognize any abnormality of morphological features in the children.

\section{Conclusion}

The current study served as a pilot study for the creation of a norm data of physical measurements for Chinese children in Hong Kong. Future confirmative studies should continue to expand and develop on the data collected in this study, with an expansion of recruitment for children and adolescent in older age groups. A validated norm data would aid in pediatricians to recognize differences and variations in children for a wide range of developmental and genetic disorders.

\section{References}

1. Leung SS, Cole TJ, Tse LY, Lau JT (1998) Body mass index reference curves for Chinese children. Ann Hum Biol 25: 169-174.

2. Wong PTY (2012) Pilot study for subgroup classification for autism spectrum disorder based on dysmorphology and physical measurements in Chinese children. The HKU Scholars Hub: The University of Hong Kong.

3. Wong VC, Fung CK, Wong PT (2014) Use of dysmorphology for subgroup classification on autism spectrum disorder in Chinese children. J Autism Disord 44: 9-18.

4. Wu KH, Tsai FJ, Li TC, Tsai CH, Peng CT, et al. (2000) Normal values of inner canthal distance, interpupillary distance and palpebral fissure length in normal Chinese children in Taiwan. Acta Paediatr Taiwan 41: 22-27.

5. APA (2000) Diagnostic and Statistical Manual of Mental Disorders (DSM-IVTR), 4th Edition. Washington, DC: American Psychiatric Association.

6. APA (2013) Diagnostic and statistical manual of mental disorders (DSM-5®) 5th edition. Arlington, VA: American Psychiatric Association.

7. Hall BD, Graham JM Jr, Cassidy SB, Opitz JM (2009) Elements of morphology: standard terminology for the periorbital region. Am J Med Genet A 149A: 29-39.
8. (2010) Growth charts. Centers for Disease Control and Prevention.

9. Wright CM, Williams AF, Elliman D, Bedford H, Birks E, et al. (2010) Using the new UK-WHO growth charts. BMJ 340: c1140.

10. Wright C, Lakshman R, Emmett P, Ong KK (2008) Implications of adopting the WHO 2006 child growth standard in the UK: two prospective cohort studies. Arch Dis Child 93: 566-569.

11. Hui LL, Schooling CM, Cowling BJ, Leung SS, Lam TH, et al. (2008) Are universal standards for optimal infant growth appropriate? Evidence from a Hong Kong chinese birth cohort. Arch Dis Child 93: 561-565.

12. Schooling CM, Hui LL, Cowling BJ, Ho LM, Leung GM (2013) Are the 2006 World Health Organization standards for infant growth applicable to Hong Kong Chinese? Universalistic standards or epidemiological transition stagespecific norms. Hong Kong Medi J 19 Suppl 9: 30-32.

13. Tam SY, Karlberg JP, Kwan EY, Tsang AM, Sheng HP, et al. (1999) Body mass index is different in normal Chinese and Caucasian infants. J Pediatr Endocrinol Metab 12: 507-517.

14. Ma J, Wang Z, Song Y, Hu P, Zhang B (2010) BMI percentile curves for Chinese children aged 7-18 years, in comparison with the WHO and the US Centers for Disease Control and Prevention references. Public Health Nutr 13: $1990-1996$

15. Lin WS, Shao LX (1997) The status of physical growth in Chinese children Coll Antropol 21: 101-108.

16. Li H, Ji CY, Zong XN, Zhang YQ (2009) Height and weight standardized growth charts for Chinese children and adolescents aged 0 to 18 years. Zhonghua Er Ke Za Zhi 47: 487-492.

17. Zong XN, Li H (2009) General growth patterns and simple mathematic models of height and weight of Chinese children. Zhonghua er ke za zhi 47 : 371-375.

18. Lee TS, Chao T, Tang RB, Hsieh CC, Chen SJ, et al. (2004) A longitudina study of growth patterns in school children in Taipei area I: growth curve and height velocity curve. J Chin Med Assoc 67: 67-72.

19. Sung RY, So HK, Choi KC, Nelson EA, Li AM, et al. (2008) Waist circumference and waist-to-height ratio of Hong Kong Chinese children. BMC Public Health 8: 324

20. Leung SF (1996) Hong Kong Growth Survey 1993. The Chinese University of Hong Kong.

21. (1996) Hong Kong growth standards data. Centre for epidemiology and Biostatics.

\section{Acknowledgements}

The authors of this paper would like to acknowledge all the principals, teachers and staff members in all the nurseries for their time and participation in the study. Sincere thank you dedicated to all the children and their families for their cooperation and support in this research. The authors of this paper declare no conflict of interest or any financial support or relationships. 